\title{
Paying for performance in healthcare organisations
}

\author{
Ruth McDonald*
}

Abstract

Aligning Financial Incentives (FIs) to health policy goals is becoming increasingly popular. In many cases, such initiatives have failed to deliver anticipated benefits. Attributing this to the actions of self-interested and resistant professionals is not an entirely helpful approach. It is important to avoid simplistic assumptions to build knowledge of how and why schemes are implemented in practice to inform future policy in this area.

Keywords: Incentives, Professionals, Quality Improvement

Copyright: $\odot 2014$ by Kerman University of Medical Sciences

Citation: McDonald R. Paying for performance in healthcare organisations. Int J Health Policy Manag 2014; 2 : 59-60. doi: 10.15171/ijhpm.2014.14
Article History:

Received: 27 December 2013

Accepted: 14 January 2014

ePublished: 17 January 2014

Correspondence to:

Ruth McDonald

Email: ruth.mcdonald@wbs.ac.uk
A ligning Financial Incentives (FIs) with policy goals is becoming increasingly popular in healthcare contexts $(1,2)$. There are many factors which are likely to influence the way in which people respond to incentives. Whilst, there are a growing number of studies quantifying the impact of incentive schemes, many fail to explore how and why health impacts do or do not occur. Much of the literature on FIs is derived from economic and psychological theory, which tends towards a view of atomistic individuals pursuing their own interests (3). Most of the social science literature examining how professionals engage with and are influenced by changes in incentive structures to date has tended to examine the impact of recent reforms drawing predominantly on economic (4) or sociological theory (5). Whilst, sociologically informed studies on the subject in relation to healthcare emphasise the importance of social and relational aspects such as shared norms, they tend to neglect the importance of the broader organisational context in which health professionals work. Linked to this, since the approach is often to ask 'what has changed following new incentive structures?' there is a danger that what has remained stable gets neglected (6).

In economic and some health policy literatures, there has been a tendency to treat FIs as a 'standard' intervention, with researchers attempting to draw conclusions about the effectiveness of these in terms of improving quality in healthcare (7). However, such initiatives vary with respect to design and the social, cultural and historical context in which they are implemented. Despite these differences, they can all be conceived as attempting to exert control over health professionals and reconfigure the landscape in which they work. Research exploring the impacts of state-sponsored reforms in healthcare settings, more generally, is often concerned to identify and categorise processes and outcomes in terms of the control of professional work and related to this, assessing the extent to which reforms result in a diminution or retention of medical power (8). One of the problems with this type of approach is that it implicitly conceptualises power in terms of a zero-sum game, and linked to this, a control-resistance framework leaves little room to accommodate more nuanced responses to reforms (9).

A small number of recent studies add a useful perspective by drawing our attention to alternative ways of examining changes to incentive structures, which do not rely on focusing on the pursuit of individual or group interests in the context of a control/ resistance framework (6). They also remind us that since financial incentive regimes are not self-implementing, mechanisms to change behaviour (e.g. electronic medical records, bespoke software to guide doctors) are needed if change is to become institutionalised. In California, for example, the failure of FIs to produce anticipated benefits was due in part to the absence of electronic records. This meant that doctors' performance was measured using claims/billing data. However, this resulted in the measurement of activities often undertaken outside of the practice-like for example, colonoscopy and mammogram rates-and less directly under the doctors' control, therefore (10). Furthermore, many doctors in the California programme were unaware of or confused by targets and related payments. A combination of multiple payers and complex payment rules contributed to a situation in which doctors were often unaware of the content of targets. Although doctors in California received feedback from their medical group on their performance against quality targets, they had concerns about the accuracy of the data used to assess performance. These findings resonate with other recent studies, which highlight how clinicians are not necessarily resistant to quality goals, linked to financial rewards, but stress the importance of mechanisms to engage them $(11,12)$.

There is some limited evidence that FIs can improve health outcomes (13). The 'Advancing Quality' initiative, in the North West of England was associated with a significant reduction in mortality. Yet, it was based on the Premier Hospital Quality Incentive Demonstration (PHQID) scheme in the US which had no impact on mortality (14). The design of the scheme, in terms of quality measures and formal rules was very similar in both countries, which suggests that the ways in which the schemes were implemented and the local contextual differences may explain differences in impacts. Whilst, the bonuses were larger in the English context, it seems likely that other factors also contributed to the relative success of the English initiative (13). This initiative is the subject of an ongoing in-depth evaluation, but the absence of detailed knowledge about the US variant makes drawing firm conclusions difficult. It also highlights the need for

*Warwick Business School, The University of Warwick, Coventry, UK 
studies to pay attention to issues beyond the formal scheme design. A focus on formal rules, in particular the size of the financial incentive, has been a preoccupation for some policy makers and academics (1). In the English NHS, the Commissioning for Quality and Innovation (CQUIN) Payment Framework linked organisational income to the achievement of quality improvement goals. In the first year of the scheme, the size of the incentive was $0.5 \%$ of the total contract income. This was increased to $1.5 \%$ after the first year and subsequently increased to $2.5 \%$. The Chief Executive of the NHS Commissioning Board is on record as saying that he would like to see this increased to $5 \%$.

A number of theories of cause and effect were contained within the CQUIN Impact Assessment prepared as part of the process of developing and implementing the CQUIN policy. CQUIN was intended to embed quality improvement and innovation through making the payment system reflect quality according to the Department of Health's Impact Assessment (15). Although a nationally mandated scheme was considered within the Impact Assessment, a scheme which encompassed mainly local goals was seen as preferable since this would ensure that clinical staff in healthcare providers would get involved in developing schemes and build on local initiatives and enthusiasm using standard metrics (15). This emphasis on local goals and provider involvement appears to have been intended to get ownership from clinical teams, thereby increasing the likelihood that desired changes would be delivered. In practice, however, mechanisms to engage clinicians were largely absent. This suggests that rather than ramping up pressure by increasing the size of the incentive, efforts should be made to understand why anticipated benefits are not forthcoming.

Whilst, it is important to learn from failure, there is some evidence that FIs can be successful in reducing inequalities in access to care (16). Incentive schemes can encourage a focus on aspects of care that are incentivised, but they can also 'crowd out' important issues, such as patient concerns (17). Furthermore, there is some evidence suggesting that rather than embedding improvements in care, FIs are associated with a diminution in performance once incentives are withdrawn (18).

In summary, in theory at least, FIs offer the opportunity to align policy goals and professional behaviour. In practice, however, for the most part, the potential benefits have not been realised. The absence of a solid evidence base has not prevented policy makers from embracing incentives as a lever for change. It is important, therefore, to build knowledge of how and why schemes are implemented in practice, in order to inform future policy in this area. In particular, studies which go beyond a 'black box' approaches and a control/ resistance framework are urgently required.

\section{Ethical issues}

Not applicable.

\section{Competing interests}

The author declares that he has no competing interests.

\section{Author's contribution}

$\mathrm{RM}$ is the single author of the manuscript.

\section{References}

1. Christianson J, Leatherman S, Sutherland K. Financial incentives for healthcare providers and quality improvement: a review of the evidence. London: Health Foundation; 2007.

2. Van Herck P, De Smedt D, Annemans L, Remmen R, Rosenthal M, Sermeus W. Systematic review: Effects, design choices, and context of pay-for-performance in health care. BMC Health Serv Res 2010; 10: 247.

3. McDonald R, Cheraghi-Sohi S, Tickle M, Roland M, Doran T, Campbell $\mathrm{S}$, et al. The impact of incentives on the behaviour and performance of primary care professionals. Report for the National Institute for Health Research Service Delivery and Organisation programme. 2010. [cited 2014 January 9]. Available from: http:// www.nets.nihr.ac.uk/_data/assets/pdf_file/0008/64295/FR-081618-158.pdf

4. Gravelle H, Sutton M, Ma A. Doctor Behaviour Under A Pay For Performance Contract: Evidence From The Quality And Outcomes Framework. Econ J 2010; 120: F129-56.

5. McDonald R, Checkland K, Harrison S, Coleman A. Rethinking collegiality: restratification in English general medical practice 2004-2008. Soc Sci Med 2009; 68: 1199-205.

6. McDonald R, Cheraghi-Sohi S, Bayes S, Kai J, Morriss R. Competing and coexisting logics in the changing field of English general medical practice. Soc Sci Med 2013; 93: 47-54.

7. Flodgren G, Eccles MP, Shepperd S, Scott A, Parmelli E, Beyer FR. An overview of reviews evaluating the effectiveness of financial incentives in changing healthcare professional behaviours and patient outcomes. Cochrane Database Syst Rev 2011; 7: CD009255.

8. Numerato D, Salvatore D, Fattore $G$. The impact of management on medical professionalism: a review. Sociol Health IIIn 2012; 34: 626-44.

9. Bolton S, Houlihan M. Beyond the control-resistance debate. Qualitative Research in Accounting \& Management 2009; 6: 5-13.

10. McDonald R, Roland M. Pay for performance in primary care in England and California: comparison of unintended consequences. Ann Fam Med 2009; 7: 121-7.

11. McDonald R, Zaidi S, Todd S, Konteh F, Hussein K, Brown S, et al. Evaluation of the Commissioning for Quality and Innovation Framework [internet]. 2013. [cited 2014 January 9]. Available from: http://www.nottingham.ac.uk/business/documents/newsdocuments/evaluation-of-the-commissioning-for-quality-andinnovation-framework---final-report---feb-2013.pdf

12. McDonald R, Zaidi S, Todd S, Konteh F, Hussein K, Roe J, et al. A Qualitative and Quantitative Evaluation of the Introduction of Best Practice Tariffs. An evaluation commissioned by the Department of Health [internet]. 2012. [cited 2014 January 9]. Available from: http://www.nottingham.ac.uk/business/documents/bpt-dh-report21nov2012.pdf

13. Sutton M, Nikolova S, Boaden R, Lester H, McDonald R, Roland M. Association between Mortality and Hospital Pay for Performance in England. N Engl J Med 2012; 367: 1821-8.

14. Jha AK, Joynt KE, Orav EJ, Epstein AM. The long-term effect of premier pay for performance on patient outcomes. $N$ Engl J Med 2012; 366: 1606-15.

15. Kristensen S, McDonald R, Sutton M. Should pay-for-performance schemes be locally designed? Evidence from the Commissioning for Quality and Innovation (CQUIN) framework. J Health Serv Res Policy 2013; 18: 38-49.

16. Doran T, Fullwood K, Kontopantelis E, Reeves D. Effect of financial incentives on inequalities in the delivery of primary clinical care in England: analysis of clinical indicators for the quality and outcomes framework. Lancet 2008; 372: 728-36.

17. Campbell $S$, McDonald $R$, Lester $H$. The experience of pay for performance in English family practice: A qualitative study. Ann Fam Med 2008; 6: 228-34.

18. Lester H, Schmittdiel J, Selby J, Fireman J, Campbell S, Lee J, et al. The impact of removing financial incentives from clinical quality indicators: longitudinal analysis of four Kaiser Permanente indicators. BMJ 2012; 340: c1898. 